\title{
Learning of human flavor preferences
}

Citation for published version (APA):

Havermans, R. C. (2016). Learning of human flavor preferences. In P. Etiévant, E. Guichard, C. Salles, \& A. Voilley (Eds.), Flavor: From food to behaviors, wellbeing and health (pp. 381-392). Woodhead

Publishing. https://doi.org/10.1016/b978-0-08-100295-7.00018-9

Document status and date:

Published: 01/01/2016

DOI:

10.1016/b978-0-08-100295-7.00018-9

Document Version:

Publisher's PDF, also known as Version of record

Document license:

Taverne

Please check the document version of this publication:

- A submitted manuscript is the version of the article upon submission and before peer-review. There can be important differences between the submitted version and the official published version of record.

People interested in the research are advised to contact the author for the final version of the publication, or visit the DOI to the publisher's website.

- The final author version and the galley proof are versions of the publication after peer review.

- The final published version features the final layout of the paper including the volume, issue and page numbers.

Link to publication

\footnotetext{
General rights rights.

- You may freely distribute the URL identifying the publication in the public portal. please follow below link for the End User Agreement:

www.umlib.nl/taverne-license

Take down policy

If you believe that this document breaches copyright please contact us at:

repository@maastrichtuniversity.nl

providing details and we will investigate your claim.
}

Copyright and moral rights for the publications made accessible in the public portal are retained by the authors and/or other copyright owners and it is a condition of accessing publications that users recognise and abide by the legal requirements associated with these

- Users may download and print one copy of any publication from the public portal for the purpose of private study or research.

- You may not further distribute the material or use it for any profit-making activity or commercial gain

If the publication is distributed under the terms of Article $25 \mathrm{fa}$ of the Dutch Copyright Act, indicated by the "Taverne" license above, 


\title{
Learning of human flavor preferences
}

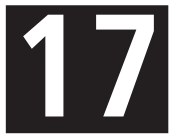

\author{
Remco C. Havermans
}

Department of Clinical Psychological Science, Faculty of Psychology and Neuroscience, Maastricht University, Maastricht, The Netherlands

\subsection{Introduction}

Living animals need to eat to survive and thrive. Eating is a necessity of life, but food can also be rewarding, and an important source of pleasure. Clearly, some foods are more rewarding than other foods. Food preferences are idiosyncratic, though only to a degree. Indeed, I contend most people prefer crisps to cauliflower. Why is that?

Man is born with few flavor preferences. Neonates like sweet taste and dislike bitter taste (Ganchrow et al., 1983). Although it is frequently argued that these are basically the only flavor preferences any person starts life with, there is some evidence that more particular preferences for given foods or dishes are heritable, and that specific taste genes are associated with specific food likes and dislikes.

A twin study by Breen et al. (2006) showed that monozygotic twins have a larger overlap in food preferences than dizygotic twins, suggesting that food preferences are, at least partly, inherited. However, an important limitation of this study was that the researchers asked the parents of the twins to indicate commonalities in food preferences. It is not hard to imagine that the parents of a monozygotic twin are biased to observe any commonality in their children, be it appearance, behavior, or indeed food preferences. Rozin and Millman (1987), when asking twins (homozygotic vs. dizygotic twins) directly about their shared food preferences, found very little evidence for heritability of flavor preferences. Twins did show greater correspondence in food likes than randomly paired subjects, but this reflects the fact that these twins were reared in the same household, while the randomly paired subjects obviously were not.

Gasparini and coworkers (Pirastu et al., 2012) tested different ethnic populations along the Silk Road-a single designation for a number of ancient trade routes connecting Mediterranean Europe with China through Central Asia-for possible links between variations of known taste genes and food preferences. The modern people living in Silk Road countries are genetically diverse, but they share a lot of culinary traditions (ie, dishes and cooking techniques). By testing the people of different Silk Road communities, Pirastu et al. found that taste gene TAS1R2 is associated with a preference for vodka and wine. Variations of a different gene (ITPR3) were associated with distaste for mutton. This is very interesting, though in line with the current contention that man is born with few flavor preferences, only 4 out of the 37 examined taste genes were found to be associated with either a like or dislike for a certain food or drink. 
To reiterate, when it comes to flavor preferences, we're nearly a blank slate. The bulk of our specific preferences, such as a liking for chips, cauliflower, or even chocolate are learned through experience. Rozin and Millman (1987) argue that this makes perfect functional sense. We humans are omnivorous, and should not be constrained in our eating by a narrow range of genetically fixed preferences. We need to be able to adapt to changes in the food environment, to learn to recognize what is edible, and what edibles are especially nutritious. Much of that learning is mediated by hedonics (Young, 1966). For example, I have the tendency to view the foods I do not like (eg, rhubarb) as inedible, and to be disgusted by the thought of having to eat a thing I do not recognize as being edible (eg, deep fried locusts).

A flavor preference, or the hedonic evaluation of a given food, is learned; acquired through experience. The present chapter describes different ways in which a food or flavor preference is acquired.

\subsection{Tasting to preference}

Mere exposure refers to an increase in liking for a particular stimulus to which one is repeatedly exposed. This can be any type of stimulus. For example, in one experiment, Zajonc (1968) exposed students to Chinese characters, told the students that these characters were adjectives, and that after being exposed to these characters they would be asked to indicate each character's "goodness" on a scale. Students were exposed to these characters with either a low or high frequency. The students regarded the high frequency characters more positively than the low frequency characters. Mere exposure to a stimulus such as a Chinese character can lead to a positive shift in attitude toward that stimulus. It is a basic phenomenon that does not require much conscious awareness, and applies to a wide variety of sensory input (Zajonc, 2001). It also applies to food.

Pliner (1982) had participants taste and rate four different tropical fruit juices. The participants were exposed 20,10, 5 times, or never to these fruit juices. Pliner found that the liking for the fruit juices depended on the number of exposures, with more exposure leading to better liking. Similarly, Birch and Marlin (1982) demonstrated in 2-year old children that repeated exposure to either novel cheeses (Experiment 1) or fruits (Experiment 2) fostered familiarity and preference for these foods.

Most children go through a phase termed neophobia - a fear for novel stimulation. It starts around 2 years of age, and peaks when approximately 6 years old (Dovey et al., 2008). In case of food, neophobia primarily concerns a reluctance to try new vegetables (Cooke et al., 2004). The results by Pliner (1982) and Birch and Marlin (1982) suggested that mere repeated exposure is an efficient way of overcoming this apparent fear of the flavor of vegetables. But how much and what kind of exposure would be necessary to achieve this?

Birch et al. (1987) conducted a study in which they exposed 2-5 year old children to different novel sweet foods (eg, figs or sugar palm). The exposure comprised either repeatedly looking at or tasting the food. Although looking increased the visual appeal of the exposed food (Heath et al., 2011), only the actual tasting of the food induced a positive shift in flavor preference. The results suggested that the mere exposure effect 
is modality specific and, thus, hinges upon actual tasting of the food. Furthermore, the study suggested that a relevant positive preference shift might require as many as 15 taste exposures (Sullivan and Birch, 1990). This number has become somewhat of a myth, though. Later studies have demonstrated that the number of exposures for a significant shift in food acceptance and liking may be much smaller. In some cases, even a single exposure to a food can be enough to promote its acceptance (Birch et al., 1998). By adding foods and dishes to one's diet, this increases the probability for sensory overlap between a newly tasted and already familiar food, thus promoting generalization of food acceptance; the "tastes-like-chicken-effect" (Havermans, 2009). Indeed, Williams et al. (2008) found that the number of exposures required for trying new food is reduced with an expanding variety of one's diet.

As for vegetable intake, Lakkakula et al. (2010) found that school children demonstrate an increase in liking for initially disliked peas, tomatoes, and carrots with 10 weekly taste exposures (Mustonen and Tuorila, 2010). Similarly, Wardle et al. (2003) instructed parents to serve their children a certain vegetable daily, for 14 days. Children who tasted the vegetable at least 10 times showed increased liking and intake for this and other vegetables, at a subsequent taste test. In sum, mere exposure is a simple technique for increasing preference and acceptance of novel foods that can be readily applied to promote healthier eating behaviors in children. However, repeat exposure can be very hard to maintain, especially when a child requires many exposures for any positive shift in vegetable liking to take hold, and when it heavily protests with each tasting. Therefore, some scholars have suggested classical (or Pavlovian) conditioning methods to facilitate the acquisition of healthy food preferences (Havermans, 2009).

\subsection{Pavlovian love of food}

Pavlov (1927) discovered that his laboratory dogs would "psychically" salivate in the presence of cues predicting food. When further investigating this psychical reflex, he systematically paired conditioned stimuli (eg, an electric buzzer, a ticking metronome, or a ringing bell) with a biologically relevant unconditioned stimulus, namely food. Food elicited the unconditioned salivary reflex in his laboratory dogs. Conditioned stimuli would also come to elicit this reflex on the condition that these stimuli reliably predicted food administration. In other words, Pavlov's dogs learned to associate the conditioned stimuli with food.

Pavlov studied conditioning, hoping to learn more about the workings of the brain and the role of the central nervous system in orchestrating digestion, but psychologists readily adopted and adapted his conditioning paradigm to demonstrate the role of associative learning in a wide range of psychological phenomena, including the acquisition of flavor preferences (Rozin and Zellner, 1985).

\subsubsection{Flavor-nutrient learning}

Mehiel and Bolles (1984) examined associative learning of flavor preferences in rats, hypothesizing that a positive nutritional outcome (eg, energy repletion) would 
reinforce a preference for a flavor associated with that outcome. The animals were food deprived, and then received one of two distinctly flavored solutions daily, in an alternating sequence, for 8 days. For half of the rats, the two flavors were isocaloric. For the other half, one flavor had a higher caloric density than the other. Only the rats in this latter group developed a preference for one of the two flavors, namely the flavor that had been relatively rich in energy. The rats had learned to associate that flavor with the functionally positive nutritional outcome of energy repletion.

Flavor-nutrient learning has also been demonstrated in humans. Kern et al. (1993) established a preference for a specifically flavored yoghurt drink in children (approximately 5 years old) by pairing the yoghurt with a relatively high fat content. Fat is the most calorically dense macronutrient $(9 \mathrm{kcal} / \mathrm{g}$ ), and so adding even small amounts of fat markedly increases the energy density of any food or drink. Apparently, the postingestive consequence of added energy promotes the acquisition of a flavor preference in children, too (Johnson et al., 1991). In line with this flavor-nutrient learning, when examining children's fruits and vegetable intake, children tend to prefer those fruits and vegetables with the highest caloric density (Gibson and Wardle, 2003).

Once established, flavor preferences are remarkably robust. They do not extinguish easily (Havermans and Jansen, 2007a). In theory, it should be possible to condition a preference for a vegetable by pairing its flavor with a positive nutritional outcome, after which one could remove the previously added macronutrients, leaving the preference intact. This is exactly what Zeinstra et al. (2009) attempted to achieve in 7-8 year old children. These children were offered two different vegetable drinks. One of these drinks had a much higher energy density (a difference of $150 \mathrm{kcal}$ ) by adding maltodextrin to it. The experimental manipulation failed. The children did not acquire a preference for the maltodextrin-enriched vegetable drink because they were extremely hesitant to taste the drinks in the first place. Flavor-nutrient learning requires a postingestive effect and, in the absence of ingestion, clearly no such effect can arise. Although flavor-nutrient learning explains why children (and adults for that matter) generally prefer high-energy dense foods such as snacks, confectionery, and chocolate, the flavor-nutrient conditioning paradigm does not easily lend itself to establish healthier food preferences.

\subsubsection{Flavor-flavor learning}

There are other options than flavor-nutrient learning for promoting flavor preferences. One alternative is positive flavor-flavor learning. This paradigm refers to a form of evaluative conditioning in which the positive valence of the so called unconditioned stimulus, due to its contiguous presentation with a neutral (or even disliked) stimulus, transfers to this latter conditioned stimulus, effectively increasing one's liking for that stimulus (De Houwer et al., 2001; Havermans, 2009; Havermans and Jansen, 2007a).

Holman (1975) studied flavor-flavor learning in rats. Rats, like humans, are born with a strong preference for sweet taste. Holman hypothesized that, in rats, sweetness functions as a reward and, hence, acts as an unconditioned stimulus reinforcing a preference for flavors consistently paired with it. Holman's rats indeed came to prefer flavored solutions paired with the sweet taste of noncaloric saccharin. 
Zellner et al. (1983) conducted an experiment on flavor-flavor learning in humans, and found that their participants, much like Holman's rats, developed a preference for flavors of tea that had consistently been sweetened during the conditioning phase. Even when at test the tea was left unsweetened, the participants still preferred its flavor.

Unlike flavor-nutrient learning, flavor-flavor learning does not hinge upon any postingestive effect. Effective flavor-flavor learning relies mainly on the sensation of an already preferred taste, such as sweet taste. Havermans and Jansen (2007b) set out to examine whether flavor-flavor learning may be applied to increase children's liking for vegetables. Children alternatingly had to take a sip from a sweetened and another unsweetened vegetable drink. With just a few sips, these children showed a positive shift in preference for the sweetened vegetable flavor, again even when at test this flavor was left unsweetened. Capaldi and Privitera (2008), using a similar flavorflavor learning paradigm, effectively conditioned a preference (or rather less of an aversion) for grapefruit in children. Further, in a randomized controlled trial, Johnston et al. (2011) examined children receiving regular vegetable tasting sessions at school. One group of these children received the vegetables together with a food they already preferred: peanut butter. After 4 months, the peanut butter group was found to eat more and a larger variety of vegetables than did the mere exposure (ie, vegetables, but no peanut butter) comparison group.

Havermans and Jansen (2007b) found no change in liking with mere repeated tastings of the unsweetened vegetable drink, and thus they concluded that flavor-flavor learning is superior to mere exposure in promoting a positive shift in food liking (Johnston et al., 2011). However, more recent studies have called this supposed superiority into question. Anzman-Frasca et al. (2012) tested toddlers, comparing a group regularly receiving vegetables paired with a favorite dip, and a group of toddlers just being exposed regularly to these vegetables. Both groups demonstrated an increase in vegetable liking. There was no difference between the two groups and, hence, the increase in liking could be attributed to mere exposure alone.

Hausner et al. (2012) examined toddlers' acceptance of a novel pureed vegetable. Toddlers were repeatedly exposed to unadulterated puree (mere exposure condition), or sweetened puree (flavor-flavor learning condition), or energy dense puree (flavor-nutrient learning condition). Intake and acceptance of the vegetable puree increased over time, but both flavor-flavor learning and flavor-nutrient learning did not appear to promote vegetable liking above and beyond mere exposure. These latter two studies suggest that flavor-flavor learning provides little benefit over mere exposure.

Interestingly, a study by Yeomans et al. (2008) suggests that flavor-flavor and flavor-nutrient learning may have additive effects on promoting flavor preferences. Participants in this study received pairings of a flavor with sucrose, or maltodextrin, or aspartame, or without any additives. Yeomans et al. measured changes in pleasantness, perceived sweetness, and intake, and found that intake increased significantly when the flavor had been paired with extra energy (maltodextrin or sucrose), but that perceived sweetness increased if the flavor had been paired with a sweet taste (aspartame or sucrose). For both pleasantness and intake, however, the data show the largest 
increase in preference for the flavor when having been paired with sucrose (both sweet and energy dense).

\subsubsection{Flavor-consequence learning}

A final form of Pavlovian conditioned food preferences concerns flavor-consequence learning. Caffeine is a methylxanthine that has been shown to reinforce flavor preferences. Richardson et al. (1996) demonstrated that participants who regularly consumed caffeine (eg, as tea, coffee, or cola) developed, over the course of 10 workdays, a positive change in liking for a fruit juice, when it was paired with the intake of a capsule containing $100 \mathrm{mg}$ of caffeine, relative to a group of participants who received a placebo with their fruit juice.

Employing a within-subject design, Yeomans et al. (2005) also found that caffeine could reinforce a preference for a novel flavor, concluding that this effect is the likely "consequence of conditioned associations between the flavor and [...] the effects of caffeine" (p. 55). This leaves the question of what exactly the reinforcing consequences of caffeine ingestion are. One obvious candidate is caffeine's psychoactive properties. Caffeine consumption makes you feel alert and energized. It increases vigilance and attention, and quickens your reaction time (Rogers and Richardson, 1993). In regular users, caffeine also alleviates possible withdrawal symptoms. These consequences of caffeine might be considered to constitute the reward that both positively and negatively reinforces a flavor preference (Rogers et al., 1995). However, theobromine, another methylxanthine, has only limited psychostimulant properties (Smit et al., 2004), and still has been found to reinforce flavor preference in much the same way as caffeine does (Smit and Blackburn, 2005).

In sum, nonnutritive substances such as methylxanthines can effectively condition a preference for paired flavors. The main reinforcing property of methylxanthines like caffeine and theobromine appears to be the alleviation of any withdrawal effects. In the case of caffeine, such withdrawal comprises dysphoric mood, deteriorated cognitive performance, fatigue, and headaches. It is not quite clear what that withdrawal comprises in the case of theobromine, though. Fig. 17.1 summarizes the role of Pavlovian learning in the acquisition of flavor preferences by providing an example of how Pavlovian conditioning can explain the acquired preference for chocolate.

\subsection{Pavlovian food cravings}

Food craving, an intense desire for a specific food item, is very common. Most people report they have experienced such craving (Weingarten and Elston, 1990). Of all foods, chocolate is the most frequently craved food (Rozin et al., 1991; Polivy et al., 2005). As the previous section describes, it is clear that Pavlovian food preference learning contributes to the palatability and, hence, desirability of foods such as chocolate. Indeed, dark chocolate is high energy dense (promoting flavor-nutrient learning), tastes sweet (promoting flavor-flavor learning), and is rich in methylxanthines (promoting flavor-consequence learning; Fig. 17.1). Chocolate is also one of 


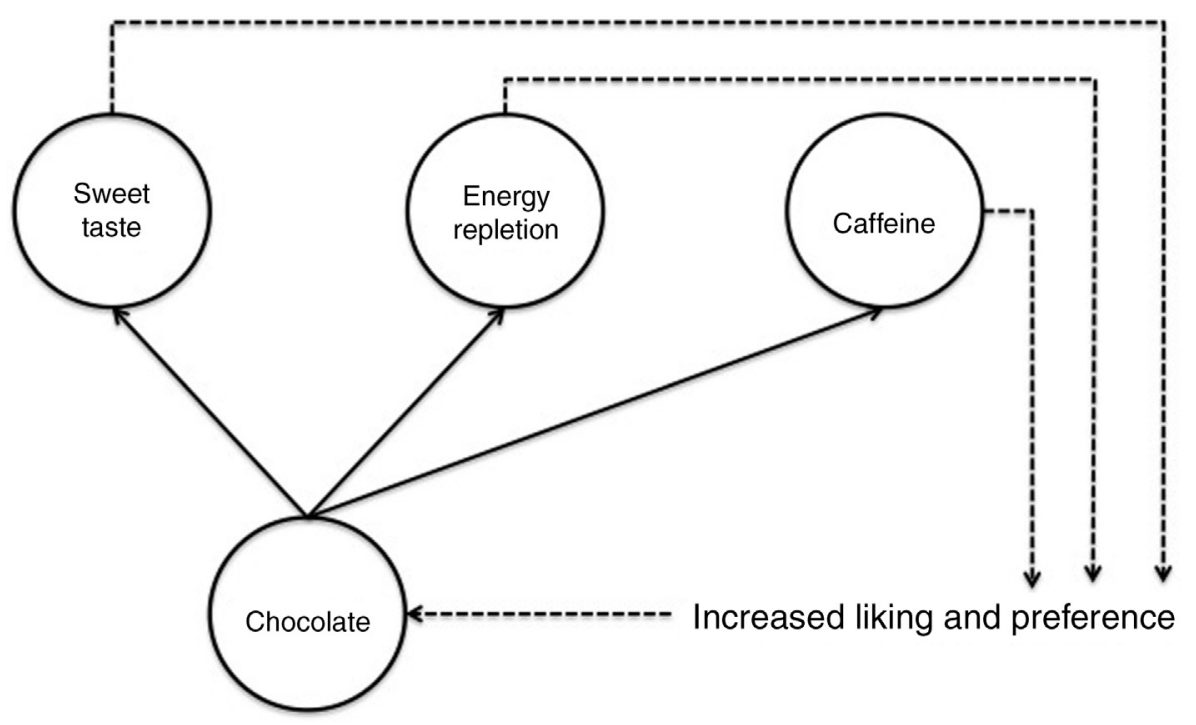

Figure 17.1 A preference for the flavor of chocolate is learned. The chocolate flavor functions as a conditioned stimulus (or CS) that, with chocolate consumption, is paired (1) with the congenitally preferred sweet taste of sugar, (2) with energy repletion, due to chocolate's high energy density, and (3) with the rewarding pharmacological consequences of chocolate's methylxanthines, like theobromine and caffeine. The various rewards associated with chocolate intake increase preference for the conditioned chocolate flavor stimulus.

the more frequently craved foods. This craving, however, cannot be simply explained in terms of chocolate's high palatability as chocolate craving, much like craving for an addictive substance, is under the control of specific cues.

Jansen (1998) argued that cue-elicited craving represents the subjective interpretation of conditioned bodily responses thought to compensate for an anticipated perturbation of homeostasis. As food intake affects internal homeostasis, the body responds by correcting or compensating for any disruptive effect. In essence, when anticipating food intake, the body prepares for digesting the food. These preparatory responses (or cephalic phase responses) include insulin release and salivation, and craving is thought to merely reflect these responses. This model nicely explains why specific food cravings are under the control of specific cues, but a problem with this view is that subjective craving does not appear to depend on the strength or even occurrence of cephalic phase responses (Havermans, 2013). That does not mean at all that Pavlovian conditioning plays no role in food cravings.

Pavlovian flavor preference learning does not just increase liking for a particular food, but also leads to the transfer of incentive value to the sensory cues (look, smell, and taste) associated with such food, or any cue that reliably predicts intake of that food. For example, the sight and smell of chocolate can be a cue that elicits strong craving for chocolate. Similarly, if you are used to eating a piece of chocolate in the 
evening, while watching an episode of your favorite television show, then eventually watching television in the evening becomes a cue that will evoke chocolate cravings.

The proposed transfer of incentive value is similar to what Berridge (2009) has termed "incentive sensitization." It is what makes food-related cues desirable in their own right. And, when exposed to these incentive cues, one experiences strong craving. Therefore, cue-elicited craving can be viewed as a Pavlovian conditioned response that directly reflects the associatively acquired incentive value of the cue (Havermans, 2013). It is not an indirect interpretation of a bodily state or response.

Craving for food can be as intense as drug craving experienced by substance dependent persons. Styn et al. (2013) exposed smokers to a stapler, a cigarette, and a bar of chocolate. Craving for either chocolate or a cigarette decreased with exposure to the neutral stapler. Cigarette craving went up with exposure to the cigarette, and chocolate craving similarly increased when being exposed to the bar of chocolate. The subjectively experienced intensity of the participants' cue-elicited craving did not depend on whether the cue was chocolate or a cigarette. This finding is in line with neurobiological research demonstrating that craving for food and craving for psychotropic substances have the same neurophysiological correlates (Tang et al., 2012).

Neurophysiological research provides ample reason to believe that food craving is similar to drug or alcohol craving. Drug or alcohol craving strongly depends on the presence of drug-related cues. Exposure to such cues typically induces in the addicted individual a marked increase in craving. For example, a habitual smoker will experience a sharp increase in his desire to smoke when having to sit next to a person who has just lit a cigarette (Havermans et al., 2003). Pelchat et al. (2004) placed participants in an MRI scanner and scanned their brain activity while they had to imagine the flavor of their favorite foods. This elicited subjective craving and this food craving was associated with increased activity in the hippocampus, caudate, and insula; brain regions that are frequently implicated in drug craving. Frankort et al. (2014) also found increased BOLD responding in the dorsal striatum (caudate nucleus and putamen) when their chocoholic participants were shown pictures of chocolate versus pictures of office supplies. Moreover, repeat chocolate exposure led to diminished cue reactivity within this brain region over time, was followed by participants reporting less and less chocolate craving. Furthermore, activation in the caudate during exposure to pictures of chocolate has been found to predict the amount of subsequent chocolate consumption in a taste test (Frankort et al., 2015).

Weingarten and Elston (1990) argued that understanding human feeding requires the consideration of food cravings. Importantly, these cravings are elicited by cues; that is, cues that predict food intake, cues that function as Pavlovian conditioned stimuli. As argued earlier, these Pavlovian cues acquire an incentive value. What that means is that they become desirable in their own right, and also motivate food-seeking behavior. A particularly prominent example of such motivating power is a phenomenon called Pavlovian-instrumental-transfer (or PIT).

Estes (1943) taught a group of rats to press a lever for food (instrumental learning phase). Next, he exposed the same rats to repeated tone-food pairings; a tone was always followed by food (Pavlovian learning phase). At test, when these rats were subsequently given the opportunity to press a lever again, they would show invigorated 


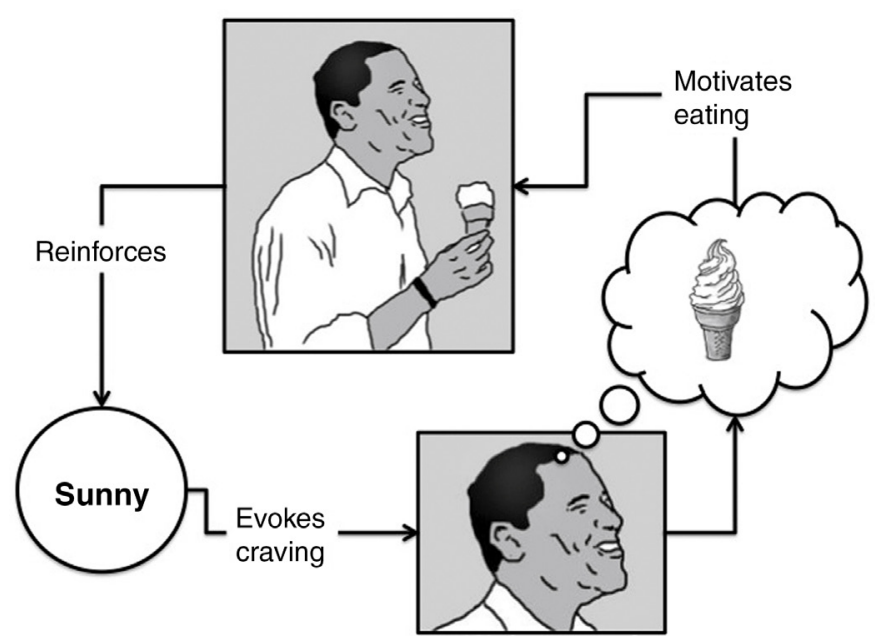

Figure 17.2 According to a Pavlovian learning perspective, any environmental cue that is reliably paired with the intake of a highly palatable food becomes associated with that food. For example, if you frequently consume ice cream with sunny weather, then sunny weather may come to function as a conditioned stimulus that-due to its acquired association with ice cream-comes to elicit craving for ice cream. This motivates intake, which then further reinforces the predictive value of sunny weather.

lever pressing for food with presentations of the tone, even though the tone had never been directly paired with lever pressing. The Pavlovian learning phase had endowed the tone with an incentive property that, at test, transferred to the instrumental lever pressing.

PIT is not limited to rats. It has been demonstrated in numerous different animal species, including humans. Interestingly, the dorsal striatum, associated with cueelicited food craving, has also been found to play an important role in PIT. Generally, any lesion within this brain region markedly reduces or even abolishes PIT (Holmes et al., 2010). Corroborating Weingarten and Elston (1990), it seems that understanding the sometimes addiction-like quality of human eating behavior requires an understanding of food craving. Fig. 17.2 displays a simple scheme of how cues are thought to come to function as Pavlovian conditioned stimuli predicting the intake of specific palatable foods. As a result, these cues then come to elicit strong desire, or craving, for that food.

\subsection{Instrumental food preferences}

Pavlovian learning mediates perceived palatability and desirability of food. Preferred foods are often not the healthiest products. Although parents and health professionals could certainly use different Pavlovian learning techniques to promote healthier flavor 
preferences, there is also the often-overlooked possibility of employing instrumental learning techniques.

Instrumental (or operant) learning refers to the learning of an association between an act and its outcome. Such conditioned behavior is purposeful. The organism responds or acts in a certain way knowing that it will have a certain consequence. For example, Skinner (1953) would teach his pigeons to peck at a certain response key through a small hole in the wall of an operant chamber, in exchange for access to food. Food serves as a reward that reinforces the behavior (key pecking in this example) that led to this reward. Is it possible to use rewards to promote healthy behavior? Could you positively reinforce the consumption of vegetables and, if so, would this adventitiously provoke increased vegetable preference?

The use of extrinsic rewards in trying to get people to act in a certain way has sometimes been viewed as a manipulative disregard for an individual's autonomy. In some ways it is, but self-interest sometimes conflicts with wider communal interests, and this means that you are occasionally asked to do things that you may not particularly enjoy doing. Remuneration for those things can motivate you to do whatever needs to be done. In case of work, such remuneration is typically called a salary. There does not appear to be anything inherently nefarious about earning a living, but, according to self-determination theory, tangible rewards for certain behavior effectively undermines intrinsic motivation for that behavior (Deci, 1971; Gagné and Deci, 2005; Ryan and Deci, 2000). Work may become less enjoyable once you get paid for it, to the detriment of the quality of your work. Rewards should thus be applied sparingly.

Self-determination theory (or cognitive evaluation theory) posits that there are limits to motivating performance with rewards, and hence there are limits to the range of behaviors one can condition by means of instrumental learning. However, this view has not gone unchallenged. In fact, a series of metaanalyses showed that there are, in fact, very few instances in which extrinsic rewards appear to undermine intrinsic motivation. Overall, only tangible rewards for already enjoyed acts undermine intrinsic motivation for such an act, and only when the reward is unrelated to level of performance (Cameron et al., 2001). So, for example, if you enjoy running (as I do), and you are competing in a 10 mile race, you will be less motivated to win the race (or complete the track in a personal best time) if you know beforehand that you will earn 1000 "eurodollar" regardless of when or even if you are going to finish the race.

There are not very many studies that have examined the effects of reward on increasing preference and intake of vegetables. Horne et al. (2011) examined the efficacy of a modeling and rewards intervention designed to increase preschool children's vegetable and fruit consumption. The children received tasting sessions at a day-care facility. They obtained individual rewards (stickers) and earned group rewards (pieces of a toy) if they tasted a served fruit or vegetable. These reward tokens effectively reinforced consumption. And this effect generalized to other fruits and vegetables (though not completely). More importantly, the increase in fruit and vegetable intake in these preschoolers persisted for at least 6 months after the program had ended, and intake was no longer rewarded. This latter result is unexpected, unless one presumes that rewards not only reinforce intake, but also promote a positive shift in flavor preference. There is evidence that it does. 
Wardle et al. (2003) compared repeated exposure and a reward-based exposure intervention to increase children's vegetable preference and intake, and found that both interventions increased children's liking and consumption over time, though the effect appeared larger with just mere exposure. More recently, Fildes et al. (2014) examined whether a low-cost parent-administered exposure and rewards intervention would increase children's liking and intake of an initially disliked vegetable. The exposure comprised 14 daily tastes of the target vegetable. Trying the vegetable was rewarded with a sticker. Liking for the target vegetable (as reported by the parents) increased, relative to a control group. Similarly, intake of the target vegetable increased significantly in the experimental group, thus showing that an exposure and reward program can effectively increase a child's acceptance of a disliked vegetable. But is a tangible reward such as a sticker really the best possible reward to increase a child's preference for an initially disliked vegetable?

Cooke et al. (2011) compared different reward-exposure programs to increase children's liking for a vegetable, namely: tangible reward and exposure; social reward and exposure; exposure without a reward. Exposure comprised 12 daily tastes of a disliked vegetable, and the three different exposure programs were compared to a no treatment control group. Relative to control, all exposure treatments increased liking for the target vegetable, and that increase was retained 3 months after treatment. There were no differences between the programs. Children consumed more of the vegetables, if they had received an exposure treatment, with or without rewards. However, increased consumption was only retained for a longer period of time in the two reward groups.

In sum, rewards (eg, stickers or compliments) reinforce the consumption of initially disliked foods such as vegetables. It also leads to increased liking for these foods. This latter effect may be an epiphenomenon due to repeated exposure to the food, rather than the direct result of the reward being associated with the flavor of the food. This would explain why rewarding vegetable intake is not necessarily more effective than mere exposure in increasing a child's acceptance of vegetables.

\subsection{Conclusions and future trends}

There are various ways of acquiring a preference for any type of food, but all these techniques share a common factor: repeated exposure. Repeatedly trying a certain food will reduce one's fear of the food, increase its acceptability, and promote a positive shift in preference. Adding an already liked food or taste to the food will also aid in increasing its acceptance. Adding nutrients or any other substance that provokes a positive postingestive effect will condition a positive shift in food liking, as well. And coaxing a subject to try a certain food by means of tangible rewards, too, may increase acceptance of the food, possibly through facilitating repeated exposure.

The implication, then, is that there are definite techniques that clearly promote preference, liking, and intake of certain food. Obviously, the food industry already applies these techniques to sell as much of their product as possible. These products are not necessarily healthy foods. It is important to realize, however, that this does not impede anyone applying these same techniques to increase a child's liking for healthier 
alternatives. As the available research discussed previously demonstrates, parents and health professionals can use mere exposure, with or without adding Pavlovian and instrumental learning techniques, to promote acceptance and even preferences for fruits and vegetables, which in turn, will contribute to an overall healthier diet.

The premise of this chapter is that most flavor preferences are acquired through learning. All learning instances focused on in the current chapter involve a form of direct experiential learning, in which any instance of learning requires the subject to experience the flavor of a food personally. Of course, there are also indirect ways of learning food preferences. People also learn about the palatability of foods by observing other people's food intake and food choice.

Jansen and Tenney (2001) tested the relative efficacy of flavor-nutrient learning and social learning in promoting primary school children's preference for yoghurt. Social learning comprised consumption of yoghurt in the context of two teachers eating their yoghurt while repeatedly praising it for its taste. Jansen and Tenney found that this social learning significantly added to the effect of flavor-nutrient learning alone. Horne et al. (2011) used a somewhat similar social modeling paradigm next to a token economy for reinforcing vegetable intake in children. This program proved to be very successful in promoting vegetable intake. Taken together, these two studies suggest that these two modes of learning (ie, associative and social learning) are complementary, but whether they also work synergistically in promoting food preferences requires further research.

\section{References}

Anzman-Frasca, S., Savage, J.S., Marini, M.E., Fisher, J.O., Birch, L.L., 2012. Repeated exposure and associative conditioning promote preschool children's liking of vegetables. Appetite 58 (2), 543-553.

Berridge, K.C., 2009. "Liking" and "wanting" food rewards: brain substrates and roles in eating disorders. Physiol. Behav. 97 (5), 537-550.

Birch, L.L., Marlin, D.W., 1982. I don't like it; I never tried it: effects of exposure on two-yearold children's food preferences. Appetite 3 (4), 353-360.

Birch, L.L., Mcphee, L., Shoba, B.C., Pirok, E., Steinberg, L., 1987. What kind of exposure reduces children's food neophobia? Looking vs. tasting. Appetite 9, 171-178.

Birch, L.L., Gunder, L., Grimm-Thomas, K., Laing, D.G., 1998. Infants' consumption of a new food enhances acceptance of similar foods. Appetite 30, 283-295.

Breen, F.M., Plomin, R., Wardle, J., 2006. Heritability of food preferences in young children. Physiol. Behav. 88, 443-447.

Cameron, J., Banko, K.M., Pierce, D., 2001. Pervasive negative effects of rewards on intrinsic motivation: the myth continues. Behav. Anal. 1 (1), 1-44.

Capaldi, E.D., Privitera, G.J., 2008. Decreasing dislike for sour and bitter in children and adults. Appetite 50 (1), 139-145.

Cooke, L., Wardle, J., Gibson, E.L., Sapochnik, M., Sheiham, A., Lawson, M., 2004. Demographic, familial and trait predictors of fruit and vegetable consumption by pre-school children. Public Health Nutr. 7, 295-302.

Cooke, L.J., Chambers, L.C., Añez, E.V., Croker, H.A., Boniface, D., Yeomans, M.R., Wardle, J., 2011. Eating for pleasure or profit: the effect of incentives on children's enjoyment of vegetables. Psychol. Sci. 22 (2), 190-196. 
De Houwer, J., Thomas, S., Baeyens, F., 2001. Associative learning of likes and dislikes: a review of 25 years of research on human evaluative conditioning. Psychol. Bull. 127, 853-869.

Deci, E.L., 1971. Effects of externally mediated rewards on intrinsic motivation. J. Pers. Soc. Psychol. 18, 105-115.

Dovey, T.M., Staples, P.A., Gibson, E.L., Halford, J.C.G., 2008. Food neophobia and "picky/ fussy" eating in children: a review. Appetite 50 (2-3), 181-193.

Estes, W.K., 1943. Discriminative conditioning I. A discriminative property of conditioned anticipation. J. Exp. Psychol. 32 (2), 150-155.

Fildes, A., Van Jaarsveld, C.H.M., Wardle, J., Cooke, L., 2014. Parent-administered exposure to increase children's vegetable acceptance: a randomized controlled trial. J. Acad. Nutr. Diet. 114 (6), 881-888.

Frankort, A., Roefs, A., Siep, N., Roebroeck, A., Havermans, R., Jansen, A., 2014. The craving stops before you feel it: neural correlates of chocolate craving during cue exposure with response prevention. Cereb. Cortex 24, 1589-1600.

Frankort, A., Roefs, A., Siep, N., Roebroeck, A., Havermans, R., Jansen, A., 2015. Neural predictors of chocolate intake following chocolate exposure. Appetite 87, 98-107.

Gagné, M., Deci, E.L., 2005. Self determination theory and work motivation. J. Organ. Behav. 26, 331-362.

Ganchrow, J., Steiner, J., Daher, M., 1983. Neonatal facial expressions in response to different qualities and intensities of gustatory stimuli. Infant Behav. Dev. 6, 189-200.

Gibson, E., Wardle, J., 2003. Energy density predicts preferences for fruit and vegetables in 4-year old children. Appetite 41, 97-98.

Hausner, H., Olsen, A., Møller, P., 2012. Mere exposure and flavour-flavour learning increase 2-3 year-old children's acceptance of a novel vegetable. Appetite 58 (3), 1152-1159.

Havermans, R.C., 2009. Increasing children's liking and intake of vegetables through experiential learning. In: Watson, R.R., Preedy, V.R. (Eds.), Bioactive Foods in Promoting Health. Academic Press, Oxford, UK, pp. 273-283.

Havermans, R.C., 2013. Pavlovian craving and overeating: a conditioned incentive model. Curr. Obes. Rep. 2, 165-170.

Havermans, R.C., Jansen, A., 2007a. Evaluative conditioning: a review and a model. Neth. J. Psychol. 63 (2), 38-49.

Havermans, R.C., Jansen, A., 2007b. Increasing children's liking of vegetables through flavour-flavour learning. Appetite 48, 259-262.

Havermans, R.C., Debaere, S., Smulders, F.T.Y., Wiers, R.W., Jansen, A.T.M., 2003. Effect of cue exposure, urge to smoke, and nicotine deprivation on cognitive performance in smokers. Psychol. Addict. Behav. 17, 336-339.

Heath, P., Houston-Price, C., Kennedy, O.B., 2011. Increasing food familiarity without the tears. A role for visual exposure? Appetite 57 (3), 832-838.

Holman, E.W., 1975. Immediate and delayed reinforcers for flavor preferences in rats. Learn. Motiv. 6, 91-100.

Holmes, N.M., Marchand, A.R., Coutureau, E., 2010. Pavlovian to instrumental transfer: a neurobehavioural perspective. Neurosci. Biobehav. Rev. 34 (8), 1277-1295.

Horne, P.J., Greenhalgh, J., Erjavec, M., Lowe, C.F., Viktor, S., Whitaker, C.J., 2011. Increasing pre-school children's consumption of fruit and vegetables. A modelling and rewards intervention. Appetite 56 (2), 375-385.

Jansen, A., 1998. A learning model of binge eating: cue reactivity and cue exposure. Behav. Res. Ther. 36 (3), 257-272.

Jansen, A., Tenney, N., 2001. Seeing mum drinking a "light" product: is social learning a stronger determinant of taste preference acquisition than caloric conditioning? Eur. J. Clin. Nutr. 55, 418-422. 
Johnson, S.L., McPhee, L., Birch, L.L., 1991. Conditioned preferences: young children prefer flavors associated with high dietary fat. Physiol. Behav. 50 (6), 1245-1251.

Johnston, C.A., Palcic, J.L., Tyler, C., Stansberry, S., Reeves, R.S., Foreyt, J.P., 2011. Increasing vegetable intake in Mexican-American youth: a randomized controlled trial. J. Am. Diet. Assoc. 111 (5), 716-720.

Kern, D.L., McPhee, L., Fisher, J., Johnson, S., Birch, L.L., 1993. The postingestive consequences of fat condition preferences for flavors associated with high dietary fat. Physiol. Behav. 54 (1), 71-76.

Lakkakula, A., Geaghan, J., Zanovec, M., Pierce, S., Tuuri, G., 2010. Repeated taste exposure increases liking for vegetables by low-income elementary school children. Appetite 55 (2), 226-231.

Mehiel, R., Bolles, R.C., 1984. Learned flavor preferences based on caloric outcome. Anim. Learn. Behav. 12, 421-427.

Mustonen, S., Tuorila, H., 2010. Sensory education decreases food neophobia score and encourages trying unfamiliar foods in 8-12-year-old children. Food Qual. Pref. 21 (4), 353-360.

Pavlov, I.P., 1927. Conditioned Reflexes. Oxford University Press, Oxford, UK.

Pelchat, M.L., Johnson, A., Chan, R., Valdez, J., Ragland, J.D., 2004. Images of desire: foodcraving activation during fMRI. NeuroImage 23 (4), 1486-1493.

Pirastu, N., Robino, A., Lanzara, C., Athanasakis, E., Esposito, L., Tepper, B.J., Gasparini, P., 2012. Genetics of food preferences: a first view from Silk Road populations. J. Food Sci. 77 (12), 413-418.

Pliner, P., 1982. The effects of mere exposure on liking for edible substances. Appetite 3 (3), 283-290.

Polivy, J., Coleman, J., Herman, C.P., 2005. The effect of deprivation on food cravings and eating behaviour in restrained and unrestrained eaters. Int. J. Eat. Disord. 38, 301-309.

Richardson, N.J., Rogers, P.J., Elliman, N.A., 1996. Conditioned flavour preferences reinforced by caffeine consumed after lunch. Physiol. Behav. 60 (1), 257-263.

Rogers, P.J., Richardson, N.J., 1993. Why do we like drinks that contain caffeine? Trends Food Sci. Technol. 4, 108-111.

Rogers, P.J., Richardson, N.J., Elliman, N.A., 1995. Overnight caffeine abstinence and negative reinforcement of preference for caffeine-containing drinks. Psychopharmacology 120 (4), 457-462.

Rozin, P., Millman, L., 1987. Family environment, not heredity, accounts for family resemblances in food preferences and attitudes: a twin study. Appetite 8, 125-134.

Rozin, P., Zellner, D., 1985. The role of Pavlovian conditioning in the acquisition of food likes and dislikes. Ann. NY Acad. Sci. 443, 189-202.

Rozin, P., Levine, E., Stoess, C., 1991. Chocolate craving and liking. Appetite 17 (3), 199-212.

Ryan, R.M., Deci, E.L., 2000. When rewards compete with nature: the undermining of intrinsic motivation and self-regulation. In: Sansone, C., Harackiewicz, J.M. (Eds.), Intrinsic and Extrinsic Motivation: The Search for Optimal Motivation and Performance. Academic Press, San Diego, CA, pp. 13-54.

Skinner, B.F., 1953. Some contributions of an experimental analysis of behavior to psychology as a whole. Am. Psychol. 8 (2), 69-78.

Smit, H.J., Blackburn, R.J., 2005. Reinforcing effects of caffeine and theobromine as found in chocolate. Psychopharmacology 181 (1), 101-106.

Smit, H.J., Gaffan, E.A., Rogers, P.J., 2004. Methylxanthines are the psycho-pharmacologically active constituents of chocolate. Psychopharmacology 176 (3), 412-419.

Styn, M.A., Bovbjerg, D.H., Lipsky, S., Erblich, J., 2013. Cue-induced cigarette and food craving: a common effect? Addict. Behav. 38 (3), 1840-1843. 
Sullivan, S.A., Birch, L.L., 1990. Pass the sugar, pass the salt: experience dictates preference. Dev. Psychol. 26 (4), 546-551.

Tang, D.W., Fellows, L.K., Small, D.M., Dagher, A., 2012. Food and drug cues activate similar brain regions: a meta-analysis of functional MRI studies. Physiol. Behav. 106 (3), 317-324.

Wardle, J., Cooke, L.J., Gibson, E.L., Sapochnik, M., Sheiham, A., Lawson, M., 2003. Increasing children's acceptance of vegetables: a randomized trial of parent-led exposure. Appetite 40 (2), 155-162.

Wardle, J., Herrera, M.-L., Cooke, L., Gibson, E.L., 2003. Modifying children's food preferences: the effects of exposure and reward on acceptance of an unfamiliar vegetable. Eur. J. Clin. Nutr. 57 (2), 341-348.

Weingarten, H.P., Elston, D., 1990. The phenomenology of food cravings. Appetite 15 (3), 231-246.

Williams, K.E., Paul, C., Pizzo, B., Riegel, K., 2008. Practice does make perfect. A longitudinal look at repeated taste exposure. Appetite 51 (3), 739-742.

Yeomans, M.R., Durlach, P.J., Tinley, E.M., 2005. Flavour liking and preference conditioned by caffeine in humans. Quart. J. Exp. Psychol. B 58 (1), 47-58.

Yeomans, M.R., Leitch, M., Gould, N.J., Mobini, S., 2008. Differential hedonic, sensory and behavioral changes associated with flavor-nutrient and flavor-flavor learning. Physiol. Behav. 93 (4-5), 798-806.

Young, P.T., 1966. Hedonic organization and regulation of behavior. Psychol. Rev. 73 (1), 59-86. Zajonc, R.B., 1968. Attitudinal effects of mere exposure. J. Pers. Soc. Psychol. 9 (Suppl.), 1-27.

Zajonc, R.B., 2001. Mere exposure: a gateway to the subliminal. Curr. Dir. Psychol. Sci. 10 (6), 224-228.

Zeinstra, G.G., Koelen, M.A., Kok, F.J., de Graaf, C., 2009. Children's hard-wired aversion to pure vegetable tastes. A 'failed' flavour-nutrient learning study. Appetite 52, 528-530.

Zellner, D.A., Rozin, P., Aron, M., Kulish, C., 1983. Conditioned enhancement of human's liking for flavor by pairing with sweetness. Learn. Motiv. 14 (3), 338-350. 